Abbreviated Key Title: Sch J Med Case Rep

ISSN 2347-9507 (Print) | ISSN 2347-6559 (Online)

Journal homepage: https://saspublishers.com

\title{
Cesarean Scar Pregnancy
}

Fouzia El Hilali $^{1 *}$, Nisrine Mamouni ${ }^{1}$, Majda Bendahhou Idrissi ${ }^{1}$, Mohamed Karam Saoud ${ }^{1}$, Sanaa Errarhay ${ }^{1}$, Chahrazed Bouchikhi ${ }^{1}$ and Abdelaziz Banani ${ }^{1}$

${ }^{1}$ Departement of gynécology-obstétrics 1, Hassan II University Hospital Center, Fez, Morocco

DOI: $10.36347 /$ sjmcr.2021.v09i04.005

| Received: 04.03.2021 | Accepted: 05.04.2021 | Published: 09.04.2021

*Corresponding author: Fouzia El Hilali

\section{Abstract}

Cesarean scar pregnancy is a rare form of ectopic pregnancy that is life-threatening due to massive hemorrhage or uterine rupture. Earlier transvaginal ultrasound of any pregnancy with a scarred uterus makes the diagnosis and avoids the complications. There is no consensus on the management of this ectopic pregnancy, an individualized therapy must be performed according to clinical and biological features, and the surgeon's expérience. We report a case of a 43 years old patient, with double scarring uterus, presented on emergency for vaginal bleeding. Transvaginal ultrasound showed a cesarean scar pregnancy. Laparotomy was performed, and on exploration: presence of a bulge at the isthmic level without defect or periferal vascularization. A small incision was made, the pregnancy was removed with lavage and suture of the uterine cavity.

Keywords: Cesarean scar, ectopic pregnancy, surgical treatment.

Copyright $(\mathcal{C} 2021$ The Author(s): This is an open-access article distributed under the terms of the Creative Commons Attribution 4.0 International License (CC BY-NC 4.0) which permits unrestricted use, distribution, and reproduction in any medium for non-commercial use provided the original author and source are credited.

\section{INTRODUCTION}

Caesarean scar pregnancy (CSP) is a rare form of ectopic pregnancy that is defined by the localization of the gestationel sac in the myometrium of a previous caesarean section scar. Its incidence is increasing due to the increase of caesarean section rates and the early screening of pregnancy, the estimated incidence according to the literature is between $1 / 1680$ and $1 / 2500$ of all pregnancies [1-3].

\section{Case Report}

A 43-year-old female patient, with a history of appendectomy, gravida 5, Para 2 with two live children each born by low transverse caesarean section and three voluntary terminations of pregnancy, the patient consulted the gynecological emergency room for vaginal bleeding with pelvic pain. Clinical examination found a conscious, hemodynamically stable patient with mucocutaneous pallor and abundant vaginal bleeding. Transvaginal ultrasound revealed an isthmic gestational sac at the level of the cesarean scar with a positive cardiac activity embryo, and a craniocaudal length at $10.2 \mathrm{~mm}$ corresponding to seven weeks of gestation and five days (Figure 1). Both ovaries were seen, with no latero-uterine mass seen, and no effusion. A laparotomy was performed, and on exploration: presence of a uterine bulge at the isthmic part without defect or peripheral vascularization (Figure 2). A small incision was made, the pregnancy was removed with lavage and suture of the uterine cavity (Figure 3).

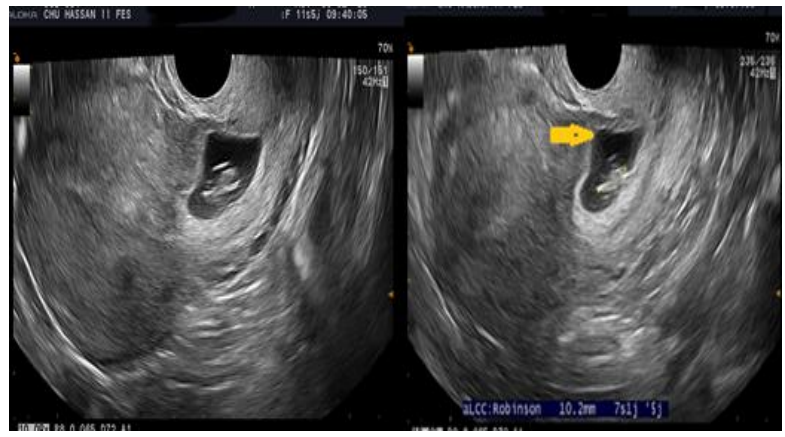

Fig-1: Empty uterine cavity with gestational sac implanted at the caesarean scar, with a 7 weeks 5 days embryo

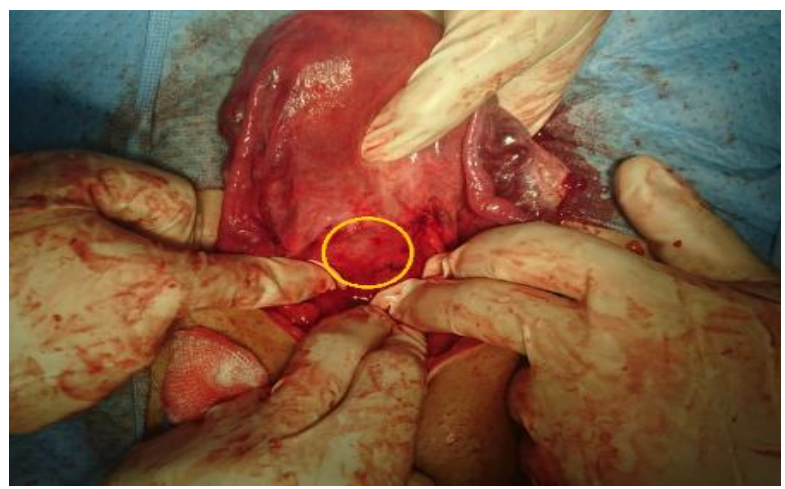

Fig-2: vesico-uterine detachment and visualization of a bulge at the istmic level without uterine wall defect 


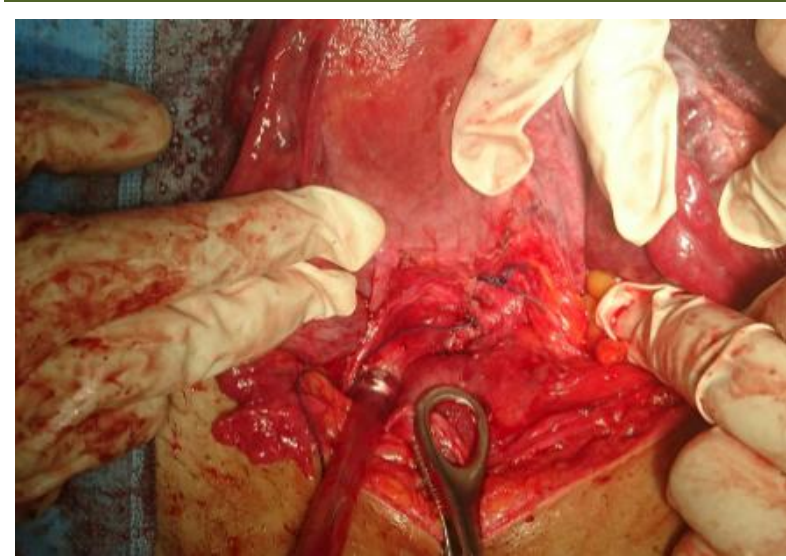

Fig-3: Suture after resection of ectopic pregnancy

\section{DISCUSSION}

Caesarean scar pregnancy is a late serious complication of cesarean section. It represents $6 \%$ of all ectopic pregnancies in women with at least one previous low uterine segment incision [4], the relationship between cesarean scar defect and CSP remains unclear. There are no specific early clinical manifestations of CSP, but this ectopic pregnancy can cause serious complications, such as abnormality of placental implantation, uterine rupture, uncontrolled hemorrhage, infertility or even death.

There are two types of CSP. Type I: with progression to the cervicoisthmic space or uterine cavity, wich could result in a viable pregnancy but with a high risk of bleeding at the placental site. Type II: with deep invasion of scar defect with progression towards bladder and abdominal cavity, it could be complicated with uterine rupture and bleeding during the first trimester in pregnancy [2, 3].

Transvaginal ultrasound (TVS) is the first-line imaging modality that allows early diagnosis based on the following criteria: empty uterine cavity; empty cervical canal and the visualization on a sagittal plane of the uterus of a gestational sac implanted in the isthmic part of the anterior uterine wall. There are also indirect ultrasound signs, such as a decrease in the thickness of the myometrium between the gestational sac and the bladder that reflects the depth of the implantation, and peri-trophoblastic hypervascularization objectified by color or energy Doppler [5].

In case of diagnostic doubt, magnetic resonance imaging (MRI) can be used to determine the anatomical reports by specifying the depth of trophoblastic invasion in the myometrium, serosa or bladder involvement and the exact position of the gestational sac [6]. MRI was found to be equally accurate in the diagnosis of CSP compared to TVS, but better for the evaluation of scar implantation [7]. Cervico-isthmic pregnancy and miscarriage in progress are the principal differential diagnoses.
Actually, there is no therapeutic consensus for this entity of ectopic pregnancy due to its rarity. Several therapeutic modalities have been proposed in the literature according to clinical, biological, and ultrasound criteria with the elaboration of decision trees [8]. The treatment, medical or surgical, remains conservative unless there is a life-threatening situation requiring a hemostasis hysterectomy.

Medical treatment is possible in a hemodynamically stable patient. It is based on local or systemic methotrexate administration or a combination of both at the dose of $1 \mathrm{mg} / \mathrm{kg}$ [9]. This treatment requires a daily follow-up of the decrease of $\beta$-hCG during hospitalization and then once a week until negativation, with ultrasound monitoring until complete disappearance of the gestational sac, with an average time required for $\beta$-hCG negativation of 4 to 6 weeks [9]. The prognostic factors for response to methotrexate treatment are the same for cervical pregnancy: absence of cardiac activity, $\beta$-hCG levels between 5,000 and $10,000 \mathrm{IU} / 1$, gestational age less than 7 weeks, and craniocaudal length less than $10 \mathrm{~mm}$ [7].

Surgical management is envisaged in case of nondesired pregnancy, hemodynamic instability, or failure of medical treatment. Several techniques have been reported in the literature according to the experience of the surgical team: Local resection of the CSP by laparoscopy or laparotomy with the possibility of bilateral ligation of the uterine or hypogastric arteries. Resection of CSP through a transvaginal approach is a novel modality recently reported with a very low complication rate [10]. Hysteroscopic evacuation is minimally invasive approach especially used for type I [1]. Uterine curettage or needle aspiration of the sac are recommended only when the thickness of the myometrium surrounding the gestational sac is $3.5 \mathrm{~mm}$ from the bladder [11]. Uterine artery embolization can be associated with all therapeutic methods and allows effective control of bleeding [12].

Some authors suggested that a local injection of methotrexate and transcervical aspiration of pregnancy should be used in preference to laparoscopy or laparotomy [3]. Although an expectant therapeutic approach has been reported despite the uncertain outcome due to the risk of placenta accreta, uterine rupture, uncontrolled hemorrhage, which may require hysterectomy $[1,2]$.

The occurrence of intrauterine pregnancy after any modality of conservative treatment has been described in the literature [5], the risk of recurrence is estimated at 5\% [13]. Some authors recommended an interval of 12 to 24 months between pregnancy with a caesarean section scar and a future pregnancy [13]. Esposito et al. [14] concluded that the interpregnancy interval was inversely associated with the probability of 
uterine scarring failure in subsequent labor. An early TVS in a later pregnancy is recommended to check the intrauterine localization of the gestational sac, with careful follow-up throughout the pregnancy due to the risk of placenta accreta. The vaginal route is accepted in the absence of any obstetrical indication for a caesarean section. In case of a history of uterine rupture during CSP or an absence of myometrium between the CSP and the bladder, Caesarean section is strongly recommended once the fetus has reached reasonable maturity, after a prenatal corticosteroid, to avoid the possible risk of spontaneous uterine rupture [5].

\section{CONCLUSiON}

Cesarean scar pregnancy is a rare form of ectopic pregnancy that is life-threatening due to hemorrhage or early uterine rupture. Transvaginal ultrasound provides an earlier diagnosis of CSP, allowing preservation of the uterus without causing maternal complications. Treatment can be conservative or radical depending on the clinical presentation, patient's age, fertility desire, $\beta$-hCG levels, imaging features, and surgeon's experience.

\section{Conflicts of interest} interest.

The authors do not declare any conflict of

\section{REFERENCES}

1. Gonzalez N, Tulandi T, Cesarean Scar Pregnancy: A systematic review, The Journal of Minimally Invasive Gynecology. 2017.

2. Ghezzi F, Laganà D, Franchi M, Fugazzola C, Bolis P. Conservative treatment by chemotherapy and uterine arteries embolization of a cesarean scar pregnancy. Eur J Obstet Gynecol Reprod Biol. 2002;103:88-91.

3. Jurkovic D, Hillaby K, Woelfer B, Lawrence A, Salim R, Elson CJ. First- trimester diagnosis and management of pregnancies implanted into the lower uterine segment cesarean section scar. Ultrasound Obstet Gynecol. 2003;21:220-7.

4. Rotas MA, Haberman S and Levgur M. Cesarean Scar Ectopic Pregnancies. Obstetrics \& Gynecology. 2006; 107(6), 1373-1381.
5. Ash A, Smith A, Maxwell D. Caesarean scar pregnancy. BJOG. 2007 Mar; 114(3): 253-263.

6. Seow KM, Huang LW, Lin YH, Yan-Sheng Lin M, Tsai YL, Hwang JL. Cesarean scar pregnancy: issues in management. Ultrasound obstet gynecol. 2004;23:247-53.

7. Kong D, Dong X, Qi Y. Ultrasonography-guided multidrug stratification interventional therapy for cesarean scar pregnancy. Arch Gynecol Obstet. 2015;292:143-8.

8. MaheutL, seconda $\mathrm{S}$, bauville $\mathrm{E}$; levêque $\mathrm{J}$. Gossesse sur cicatrice de césartienne: un cas clinique de traitement conservateur. Journal de gynecologie obstetrique et biologie de reproduction. 2010; 39(3): 254-258.

9. Nawroth F, Foth D, Wilhelm L, Schmidt T, Warm M, Römer T. Conservative treatment of ectopic pregnancy in a cesarean section scar with methotrexate: a case report. Eur J Obstet Gynecol Reprod Biol. 2001 Nov; 99(1): 135-137.

10. Birch Petersen K, Hoffmann E, Rifbjerg Larsen C and Nielsen HS. Cesarean scar pregnancy: a systematic review of treatment studies. Fertility and Sterility. 2016; 105(4), 958-967.

11. Ozdamar O, Doger E, Arlier S, Cakiroglu Y, Ergn RN, Kopuk SY. Exogenous cesarean scar pregnancies managed by suction curettage alone or in combination with other therapeutic procedures: A series of 33 cases and analysis of complication profile. J Obstet Gynaecol Res.

12. Imbar T, Bloom A, Ushakov F, Yagel S. Uterine artery embolization to control hemorrhage after termination of pregnancy implanted in a cesarean delivery scar. J Ultrasound Med. 2003 Oct; 22(10): 1111-1115.

13. Ben Nagi J, Helmy S, Ofili-Yebovi D, Yazbek J, Sawyer E, Jurkovic D. Reproductive outcomes of women with a previous history of Caesarean scar ectopic pregnancies. Hum Reprod. 2007 Jul; 22(7): 2012-2015.

14. Esposito MA, Menihan CA, Malee MP. Association of interpregnancy interval with uterine scar failure in labor: a case-control study. Am J Obstet Gynecol. 2000;183: 1180-3. 